Research Article

\title{
Prevalence and Influencing Factors of Overweight and Obesity among Adult Residents of Western China: A Cross- Sectional Study
}

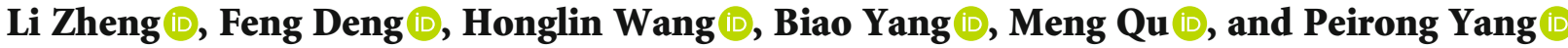 \\ Baoji Center for Disease Control and Prevention, Baoji 721000, China \\ Correspondence should be addressed to Feng Deng; bjwzy68@126.com
}

Received 1 April 2021; Revised 30 September 2021; Accepted 1 October 2021; Published 13 October 2021

Academic Editor: Fabrizio Stracci

Copyright (c) $2021 \mathrm{Li}$ Zheng et al. This is an open access article distributed under the Creative Commons Attribution License, which permits unrestricted use, distribution, and reproduction in any medium, provided the original work is properly cited.

\begin{abstract}
Background. Overweight and obesity have become a serious health problem. There are a few data on the prevalence of overweight and obesity in Baoji city of western China, this study was conducted to investigate the epidemiologic features of overweight and obesity and explored influencing factors among Baoji adult residents. Methods. A cross-sectional study, including 36,600 participants aged above 15 years, was carried out in Baoji city in 2018. Each participant's weight and height were measured, and demographic and behavioral characteristics were collected using questionnaires. Data were analyzed by means of logistic regression considering 95\% level of significance. Results. Overall, the prevalence of overweight and obesity was $30.73 \%$ and $3.11 \%$, respectively. Male had a significantly higher prevalence of overweight $(31.45 \%$ vs. $29.98 \%, P<0.05)$ while female had a higher prevalence of obesity $(3.50$ vs. $2.74, P<0.001)$. In the logistic regression analysis, being married or living with a partner $(\mathrm{OR}=1.266, P<0.001)$, unemployed or retired $(\mathrm{OR}=1.183, P<0.001)$, former smokers $(\mathrm{OR}=1.116, P<0.05)$, drinking alcohol $(\mathrm{OR}=1.410, P<0.001)$, sleeping more than 10 hours $(\mathrm{OR}=1.274, P<0.001)$, and increasing age were all significantly associated with a higher prevalence of overweight/obesity, whereas people who lived in rural areas $(R=0.904, P<0.001)$ or had a sufficient leisure time physical activity per week $(R=0.945, P<0.05)$ were associated with a lower prevalence. Conclusion. Our results demonstrate that demographic and behavioral factors play an important role in prevalence of overweight/obesity, which can support the implementation of interventions aimed at weight control and consequently prevention of related diseases in this population.
\end{abstract}

\section{Introduction}

Obesity has become a major public health problem; according to a recent report by the $\mathrm{WHO}$, more than 1.9 billion adults were overweight, and of these over 650 million were obese, the worldwide prevalence of obesity nearly tripled between 1975 and 2016 [1]. The effect of overweight and obesity on health has been well documented in the literature; they are major risk factors for a number of chronic diseases, including diabetes, hypertension, musculoskeletal disorders, cardiovascular diseases, and some types of cancer [2].

Researchers found the prevalence of overweight and obesity varied across countries in the levels and trends with distinct regional patterns, and there were likely to be continued increases of obesity epidemic in developing countries [3]. As is known to all, China is the largest developing country, with a large economic development over the past several decades. Its rapid economic growth has provoked many changes in lifestyles involving dietary habits and physical activity, which have contributed to an increase in body weight [4]. Recent studies suggest that the prevalence of overweight and obesity in the Chinese population increased from $37.4 \%$ to $41.2 \%$ and $8.6 \%$ to $12.9 \%$ between 2000 and 2014 , with an estimated increase of $0.27 \%$ and $0.32 \%$ per year, respectively [5]. Hence, prevention and control of overweight and obesity are of great urgency in China.

The rise in overweight and obesity arouse wide public concern and has led to widespread calls for regular monitoring of changes in overweight and obesity prevalence in all populations. The Chinese government has realized the 
importance of obesity control and issued Health China Action (2019-2030), which lists reducing the growth rate of obesity as one of its key tasks. Baoji city is located in western China, the less developed areas. To date, this is the first large representative population-based survey of chronic diseases in this area; the aims of this study were to provide the recent estimates of the prevalence of overweight and obesity and to explore potential influencing factors in western China, which will useful for policy makers in formulating policies for obesity management.

\section{Methods}

2.1. Subjects. Data for the present study was from the Prevalence of Major Chronic Diseases and Related Risk Factors Survey in Baoji city, western China. This was a populationbased cross-sectional survey; we used a multistage cluster sampling method to select a representative sample of people aged above 15 years. The first stage covered all twelve districts and counties in Baoji city. Second, five streets (for urban areas) or towns (for rural areas) were selected from each district or county using the probability-proportionalto-size (PPS) method. Third, four neighbourhood committees (for urban areas) or villages (for rural areas) were further randomly selected from each street (for urban areas) or town (for rural areas), also using the PPS method. Fourth, in each neighbourhood committees (for urban areas) or village (for rural areas), fifty-sixty households were randomly chosen using the simple random sampling method. In the final stage, one person aged above 15 years, who was a local registered resident for more than 6 months was selected randomly from each chosen household using a Kish selection table. The ultimate target sample size was established to be 37,000, while 400 participants with missing information such as gender, age, weight, and height were excluded; therefore, 36,600 participants were included in the analysis, accounting for about $11 \%$ of the total adult population of Baoji city. This work was approved by Baoji Center for Disease Control and Prevention Academic Ethics Board. Written informed consent was acquired from each participant in the survey.

2.2. Data Collection. Participants were required to complete a questionnaire to collect demographic characteristics (including age, gender, location, marital status, education, and occupation) and behavioral characteristics (including smoking, drinking, sleep duration, and physical activity) through face-to-face interviews by trained medical staff. Body height and weight were measured without shoes, and in light clothing after overnight fasting, height was measured to the nearest $0.1 \mathrm{~cm}$, and weight was measured to the nearest $0.1 \mathrm{~kg}$.

2.3. Definition of Variables. Overweight and obesity were defined as a BMI of $24-27.9 \mathrm{~kg} / \mathrm{m}^{2}$ and a $B M I \geq 28 \mathrm{~kg} / \mathrm{m}^{2}$, respectively, by the Chinese standards [6]. Education was classified into three levels: primary school and lower (receiving only primary education or no education); middle school (including junior middle school, senior middle school, and secondary vocational schooling); and college and higher. The occupations consisted of three parts: manual worker, nonmanual worker, and unemployed and retired people. Smoking status was categorized into: current, former, or never smoker [7]. A drinker was defined as a person who had consumed more than one alcoholic drink a week during the previous year, including any form of alcohol [8]. Sleep duration was classified into four levels: $<6 \mathrm{~h}, 6-8 \mathrm{~h}, 8-10 \mathrm{~h}$, and $>10 \mathrm{~h}$; " $<6 \mathrm{~h}$ " was defined as persons who slept less than 6 hours over 3 days a week, and those who slept more than 10 hours over 3 days a week were defined as " $>10 \mathrm{~h}$ " [9]. Physical activity recommendations of the WHO for health were considered to be satisfied if participants reported engaging in at least 150 minutes of moderate-intensity aerobic physical activity or 75 minutes of vigorous intensity activity throughout the week or an equivalent combination of moderate and vigorous intensity activity [10]. To assess leisure time physical activity, participants were asked to report the number of exercise days in a usual week, duration of exercise per day, and exercise intensity. We classified leisure time physical activity level in this study as sufficient versus insufficient.

2.4. Statistical Analysis. Categorical variables were described as numbers and percentages. Continuous variables were presented as the mean \pm standard derivation (SD). Betweengroup differences in participant characteristics were tested using a $t$-test for continuous variables and chi-square/Cochran-Mantel-Haenszel test for categorical variables. Separate univariate analyses were used to identify those variables associated with overweight/obesity among subjects in the populations studied. All these significant variables were included in the multivariable logistic regression models. Results of logistic regression analysis were presented together with OR and 95\% confidence intervals (CI). All statistical analyses were conducted using IBM SPSS Statistics Version 19.0, and a $P \leq 0.05$ was considered statistically significant.

\section{Results}

3.1. Basic Characteristics. The basic characteristics of the study participants are illustrated in Table 1. A total of 36,600 participants were included in the analysis, including 18,676 (51.03\%) males and 17,924 (48.97\%) females and $52.33 \%$ lived in urban areas and $47.67 \%$ lived in rural areas. The mean age of $41.61 \pm 16.32$ years. More than three quarters $(75.37 \%)$ of the residents were married or living with a partner, $60.43 \%$ had an education level of middle school, and $73.62 \%$ were manual worker. Current smokers and alcohol drinkers accounted for $17.46 \%$ and $5.84 \%$. About $31.18 \%$ of participants had a sufficient leisure time physical activity. Compared with females, males showed higher values for height, weight, and BMI.

3.2. Prevalence of Overweight and Obesity. The overall prevalence of overweight and obesity was $30.73 \%$ and $3.11 \%$ in Baoji (Table 2). In males, $31.45 \%$ were overweight and $2.74 \%$ were obesity. Likewise, $29.98 \%$ were overweight and 
Table 1: Descriptive characteristics of participants in Baoji, western China.

\begin{tabular}{|c|c|c|c|}
\hline Characteristic & Male & Female & Total \\
\hline Number, $n(\%)$ & $18676(51.03)$ & $17924(48.97)$ & $36600(100)$ \\
\hline Age (years), mean (SD) & $41.00 \pm 16.36$ & $42.24 \pm 16.26$ & $41.61 \pm 16.32$ \\
\hline \multicolumn{4}{|l|}{ Location, $n(\%)^{*}$} \\
\hline Urban & $9595(51.38)$ & $9557(53.32)$ & $19152(52.33)$ \\
\hline Rural & $9081(48.62)$ & $8367(46.68)$ & $17558(47.67)$ \\
\hline \multicolumn{4}{|l|}{ Marriage, $n(\%)^{*}$} \\
\hline Single & $4646(24.88)$ & $3139(17.51)$ & $7785(21.27)$ \\
\hline Married or living with a partner & $13464(72.09)$ & $14120(78.78)$ & $27584(75.37)$ \\
\hline Separated, divorced, or widowed & $566(3.03)$ & $665(3.71)$ & $1231(3.36)$ \\
\hline \multicolumn{4}{|l|}{ Education, $n(\%)^{*}$} \\
\hline Primary school and lower & $3879(20.77)$ & $5864(32.72)$ & $9743(26.62)$ \\
\hline Middle school & $12222(65.44)$ & $9897(55.22)$ & $22119(60.43)$ \\
\hline College and higher & $2575(13.79)$ & $2163(12.07)$ & $4738(12.95)$ \\
\hline \multicolumn{4}{|l|}{ Occupation, $n(\%)^{*}$} \\
\hline Manual worker & $13968(74.79)$ & $12978(72.41)$ & $26946(73.62)$ \\
\hline Nonmanual worker & $3350(17.94)$ & $3026(16.88)$ & $6376(17.42)$ \\
\hline Unemployed or retired & $1358(7.27)$ & $1920(10.71)$ & $3278(8.96)$ \\
\hline \multicolumn{4}{|l|}{ Smokers, $n(\%)^{*}$} \\
\hline Never & $11301(60.51)$ & $16931(94.46)$ & $28232(77.14)$ \\
\hline Former & $1519(8.13)$ & $460(2.57)$ & $1979(5.41)$ \\
\hline Current & $5856(31.36)$ & $533(2.97)$ & $6389(17.46)$ \\
\hline Drinkers, $n(\%)^{*}$ & $1871(10.02)$ & $267(1.49)$ & $2138(5.84)$ \\
\hline \multicolumn{4}{|l|}{ Physical activity, $n(\%)$} \\
\hline Insufficient & $12866(68.89)$ & $12323(68.75)$ & $25189(68.82)$ \\
\hline Sufficient & $5810(31.11)$ & $5601(31.25)$ & $11411(31.18)$ \\
\hline Height $(\mathrm{cm})$, mean $(\mathrm{SD})^{*}$ & $168.98 \pm 6.25$ & $162.85 \pm 5.70$ & $165.98 \pm 6.73$ \\
\hline Weight $(\mathrm{cm})$, mean $(\mathrm{SD})^{*}$ & $65.53 \pm 8.03$ & $60.60 \pm 7.13$ & $63.12 \pm 7.99$ \\
\hline BMI $\left(\mathrm{kg} / \mathrm{m}^{2}\right)$, mean $(\mathrm{SD})^{\#}$ & $22.95 \pm 2.54$ & $22.88 \pm 2.72$ & $22.92 \pm 2.63$ \\
\hline
\end{tabular}

Data are represented as the value (percentage) or mean \pm SD. BMI: body mass index; SD: standard derivation. ${ }^{*} p<0.001$ when comparing male with female. ${ }^{\#} p<0.05$ when comparing male with female.

$3.50 \%$ were obesity in females. According to the WHO BMI classification, the prevalence of overweight (BMI 25$\left.29.9 \mathrm{~kg} / \mathrm{m}^{2}\right)$ and obesity $\left(\mathrm{BMI} \geq 30 \mathrm{~kg} / \mathrm{m}^{2}\right)$ was $20.43 \%$ (19.51\% in male, $21.40 \%$ in female) and $0.78 \%(0.67 \%$ in male, $0.90 \%$ in female), respectively.

As shown in Figure 1, the prevalence of overweight for male increased with age, peaking at 55 64 years (37.25\%); such age trend was not seen in the prevalence of obesity. For female, a gradual increase was noted in the prevalence of overweight from the youngest age group (25.53\%) up to the group aged above 65 years $(36.11 \%)$, while the prevalence of obesity reached its peak at the group aged 55 64 years (5.35\%) and then followed by a decline in the higher age group. Moreover, the prevalence of overweight was higher in male than in female in the group aged over 25 years, and the prevalence of obesity was higher in female than in male in the age group 15 24 and aged above 45 years.

The prevalence of overweight and obesity was higher $(33.06 \%, 3.63 \%)$ among participants who were married or living with a partner than people who were separated, divorced, or widowed $(31.84 \%, 2.94 \%)$ or who were single $(22.31 \%, 1.30 \%)$. The higher prevalence of overweight or obesity was found in unemployed and retired people $(35.54 \%, 3.63 \%)$. A lower educational level was also associated with higher prevalence of overweight and obesity. As with people residing in rural areas, participants who have a sufficient leisure time physical activity also had a lower prevalence of overweight/obesity. Overweight/obesity was also more prevalent among former smokers and drinkers. In addition, prevalence of overweight was higher (35.86\%) in participants who had a $\geq 10$-hour sleep duration, while the highest prevalence of obesity (5.86\%) was found in participants with $<6$-hour sleep duration.

3.3. Related Factors for Overweight/Obesity. All significant factors in Table 2 added to the multivariate logistic regression model to assess the significant determinants of combined overweight and obesity (overweight/obesity), as seen in Table 3. Compared with participants aged 15-24 years, people aged $35-44$ years, $45-54$ years, 55-64 years, and $\geq 65$ 
TABLE 2: Prevalence of overweight and obesity among various characteristics.

\begin{tabular}{|c|c|c|c|c|c|c|}
\hline & \multicolumn{2}{|c|}{ Overweight } & \multicolumn{2}{|c|}{ Obesity } & \multicolumn{2}{|c|}{ Overweight/obesity } \\
\hline & No. (\%) & $P$ value & No. (\%) & $P$ value & No. (\%) & $P$ value \\
\hline Total & $11248(30.73)$ & & $1138(3.11)$ & & $12386(33.84)$ & \\
\hline Gender & & 0.002 & & $<0.001$ & & 0.152 \\
\hline Male & $5874(31.45)$ & & $511(2.74)$ & & $6385(34.19)$ & \\
\hline Female & $5374(29.98)$ & & $627(3.50)$ & & $6001(33.48)$ & \\
\hline Location & & $<0.001$ & & 0.117 & & $<0.001$ \\
\hline Urban & $6139(32.05)$ & & $569(2.97)$ & & $6708(35.03)$ & \\
\hline Rural & $5109(29.28)$ & & $569(3.26)$ & & $5678(32.54)$ & \\
\hline Age group (years) & & $<0.001$ & & $<0.001$ & & $<0.001$ \\
\hline $15-$ & $1698(22.18)$ & & $92(1.20)$ & & $1790(23.38)$ & \\
\hline $25-$ & $1611(27.68)$ & & $128(2.20)$ & & $1739(29.87)$ & \\
\hline $35-$ & $2565(32.35)$ & & $285(3.59)$ & & $2850(35.95)$ & \\
\hline $45-$ & $2281(34.44)$ & & $273(4.12)$ & & $2554(38.56)$ & \\
\hline $55-$ & $1751(35.73)$ & & $220(4.49)$ & & $1971(40.22)$ & \\
\hline$\geq 65$ & $1342(36.56)$ & & $140(3.81)$ & & $1482(40.37)$ & \\
\hline Marriage & & $<0.001$ & & $<0.001$ & & $<0.001$ \\
\hline Single & $1737(22.31)$ & & $101(1.30)$ & & $1838(23.61)$ & \\
\hline Married or living with a partner & $9100(33.06)$ & & $999(3.63)$ & & $10099(36.61)$ & \\
\hline Separated, divorced, or widowed & $411(31.84)$ & & $38(2.94)$ & & 449 (36.47) & \\
\hline Education & & $<0.001$ & & $<0.001$ & & $<0.001$ \\
\hline Primary school and lower & $3181(32.65)$ & & $398(4.08)$ & & $3579(36.73)$ & \\
\hline Middle school & $6710(30.34)$ & & $666(3.01)$ & & $7376(33.35)$ & \\
\hline College and higher & $1357(28.64)$ & & $74(1.56)$ & & $1431(30.20)$ & \\
\hline \multicolumn{7}{|l|}{ Occupation } \\
\hline Manual & $8427(31.27)$ & $<0.001$ & $926(3.44)$ & $<0.001$ & $9353(34.71)$ & $<0.001$ \\
\hline Nonmanual & $1656(25.97)$ & & $93(1.46)$ & & $1749(27.43)$ & \\
\hline Unemployed & $1165(35.54)$ & & $119(3.63)$ & & $1284(39.17)$ & \\
\hline \multicolumn{7}{|l|}{ Smoker } \\
\hline Never & $8346(29.56)$ & $<0.001$ & $874(3.10)$ & 0.033 & $9220(32.66)$ & $<0.001$ \\
\hline Former & $702(35.47)$ & & $80(4.04)$ & & $782(39.51)$ & \\
\hline Current & $2200(34.43)$ & & $184(2.88)$ & & $2384(37.31)$ & \\
\hline Drinker & & $<0.001$ & & 0.062 & & $<0.001$ \\
\hline Yes & 845 (39.52) & & $81(3.79)$ & & $926(43.31)$ & \\
\hline No & $10403(30.19)$ & & $1057(3.07)$ & & $11460(33.25)$ & \\
\hline Physical activity & & $<0.001$ & & 0.323 & & 0.001 \\
\hline Insufficient & $7892(31.33)$ & & $768(3.05)$ & & $8660(34.38)$ & \\
\hline Sufficient & $3356(29.41)$ & & $370(3.24)$ & & $3726(32.65)$ & \\
\hline Sleep duration & & $<0.001$ & & $<0.001$ & & $<0.001$ \\
\hline$<6 \mathrm{~h}$ & $295(30.86)$ & & $56(5.86)$ & & $351(36.72)$ & \\
\hline $6-8 \mathrm{~h}$ & $5308(30.77)$ & & $500(2.90)$ & & $5808(33.67)$ & \\
\hline $8-10 \mathrm{~h}$ & $5101(30.23)$ & & $533(3.16)$ & & $5634(33.39)$ & \\
\hline$\geq 10$ & $544(35.86)$ & & $49(3.23)$ & & 593 (39.09) & \\
\hline
\end{tabular}

Data are represented as value (percentage). Overweight: BMI $24-27.9 \mathrm{~kg} / \mathrm{m}^{2}$; obesity: BMI $\geq 28 \mathrm{~kg} / \mathrm{m}^{2}$; overweight $/$ obesity: BMI $\geq 24 \mathrm{~kg} / \mathrm{m}^{2}$.

years had a greater correlation with developing overweight and obesity (all $P<0.001$ ). Overweight/obesity seems to increase for participants who have been married or living with a partner $(\mathrm{OR}=1.266, P<0.001)$, unemployed and retired people $(\mathrm{OR}=1.183, P<0.001)$, former smokers
$(\mathrm{OR}=1.116, P<0.05)$, drinking alcohol $(\mathrm{OR}=1.410, P<$ $0.001)$, and those sleeping more than 10 hours $(\mathrm{OR}=1.274$, $P<0.001)$ and decrease with people who lived in rural areas and had a sufficient leisure time physical activity $(R=0904$, $P<0.001 ; R=0.945, P<0.05)$. 


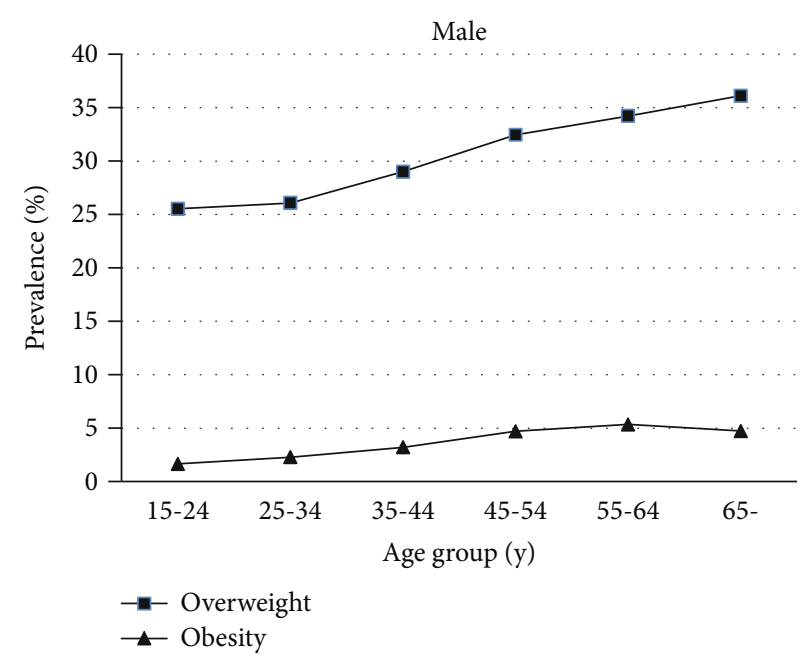

(a)

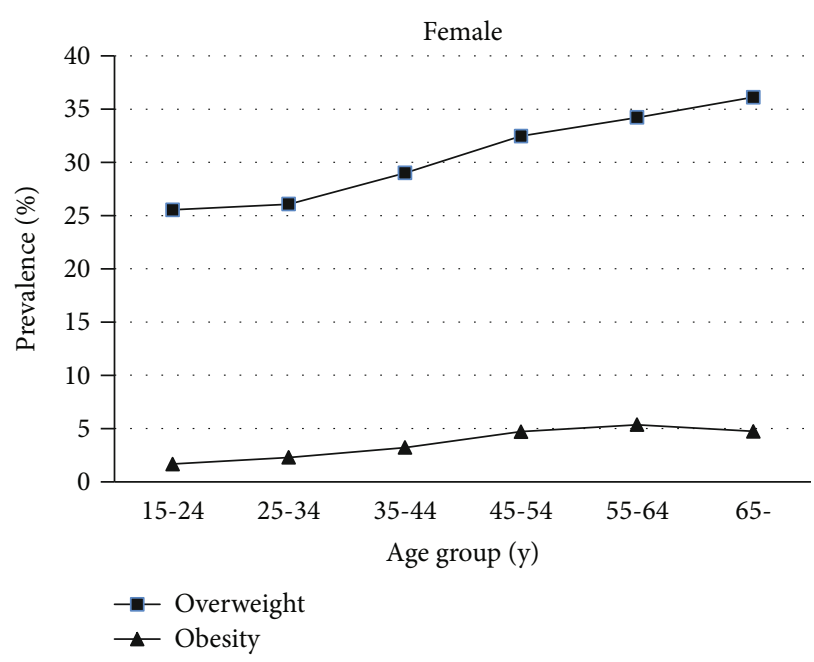

(b)

FIgURE 1: Prevalence of overweight and obesity by different age groups in (a) males and (b) females.

\section{Discussion}

Baoji is located in western China with a low level of economic development; there are few data and studies on overweight and obesity. The present study represents the first attempt to examine the prevalence and explore related factors of overweight and obesity in Baoji, using the most recent data from a large representative sample.

The prevalence of overweight and obesity was 30.73\% and $3.11 \%$ in the analyzed population in Baoji; standardized prevalence by Chinese census data was $30.66 \%$ and $3.08 \%$. The prevalence of overweight was comparable to the national level of $30.1 \%$, while obesity was lower than the national level of $11.9 \%$ [11]. The figures reported from other regions conducted in China have varied considerably: a study in Jilin province of northeast China in 2012 indicated that the prevalence of overweight and obesity was $32.3 \%$ and $14.6 \%$ [12]; figures in Zhejiang province of eastern China in 2012 were $32.0 \%$ and $6.7 \%$ [13], while the prevalence was $25.8 \%$ and $7.9 \%$ in 2014 in Jiangxi province located in eastern China [14]. It was noted that the prevalence of obesity observed in our study population is considerably lower than the values reported in other regions, but comparable to that of Hanzhong city, northwest China [15]. Differences in the prevalence of overweight and obesity may be due to economic development level, sociodemographic variables, climate or lifestyle habits, and economic development levels [16].

Our study indicated that male has a slightly higher prevalence of overweight than female (31.45\% vs. $29.98 \%)$, while a negative association was found with obesity $(2.74 \%$ vs. 3.50 ), as found in a study including 31 countries' samples based on the International Social Survey Program $(38.2 \%$ vs. $25.5 \%, 12.1 \%$ vs. $12.5 \%$ ) [17]. However, in the multivariate analysis, it showed there was no significant gender difference of combined overweight and obesity. Yet, most literatures have found the prevalence of obesity in adults was greater for female than for male, and researchers have also identified biological, behavioral, and socioeconomic fac- tors contributing to the differences in obesity prevalence between genders [18].

Our study found overweight/obesity was more common in urban than in rural areas (35.03\% vs. $32.54 \%$ ), as found in other studies [19]. Along with economic growth and the urbanization of lifestyle in China, the prevalence of overweight/obesity among both urban and rural residents has been on the rise; of particular significance, the disparity between them is narrowing. Studies from four large-scale surveys in China between 2000 and 2014 found the prevalence of overweight in the general Chinese population was $38.9 \%$ for urban residents and $34.3 \%$ for rural residents in 2000 ; by 2014 , the prevalence was $41.4 \%$ for urban residents and $40.7 \%$ for rural residents [5]. For a large, but economically unevenly developed country like China, an appreciation of the regional distribution of obesity would be informative with respect to understanding the obesityrelated health issues. The long-term trends in overweight/obesity for urban and rural residents in western China, the less developed areas, have not been characterised clearly, and it needs to be studied in the future.

It is important to note that ageing also contributes to a higher prevalence of overweight and obesity; the general prevalence reached its peak at group aged above 65 years and 55 64 years, which is consistent with a study in Beijing [20]. It also should be noted that the prevalence of obesity was higher at a younger age (35 44 years) for male, which may be related to the increasing work pressure, decreased physical activity, and unhealthy lifestyle. Another emerging challenge that should not be ignored is the change in food shopping habits induced by the fast growing online-tooffline food delivery service in China, which may decrease the amount of individual physical activity by keeping people at worksite or home and likely raise the risk of being overweight or obesity $[21,22]$. Interestingly, we found the prevalence of obesity was higher in female aged above 45 years than in male, aside from the hormone changes during menopausal transition that also could be partly explained by the fact that young women paid more attention to their body 
TABLE 3: Factors associated with overweight/obesity by multivariate logistic regression analysis in Baoji adults.

\begin{tabular}{|c|c|c|}
\hline & \multicolumn{2}{|c|}{ Overweight/obesity } \\
\hline & OR $(95 \% \mathrm{CI})$ & $P$ value \\
\hline \multicolumn{3}{|l|}{ Age (years) } \\
\hline $15-25$ & 1 & \\
\hline $25-34$ & $1.167(1.056 \sim 1.290)$ & $<0.001$ \\
\hline $35-44$ & $1.496(1.350 \sim 1.658)$ & $<0.001$ \\
\hline $45-54$ & $1.697(1.527 \sim 1.887)$ & $<0.001$ \\
\hline $55-64$ & $1.828(1.634 \sim 2.045)$ & $<0.001$ \\
\hline$\geq 65$ & $1.820(1.611 \sim .055)$ & $<0.001$ \\
\hline \multicolumn{3}{|l|}{ Location } \\
\hline Urban & 1 & \\
\hline Rural & $0.904(0.863 \sim 0.947)$ & $<0.001$ \\
\hline \multicolumn{3}{|l|}{ Marriage } \\
\hline Single & 1 & \\
\hline Married or living with a partner & $1.266(1.153 \sim 1.390)$ & $<0.001$ \\
\hline Separated, divorced, or widowed & $1.130(0.972 \sim 1.315)$ & 0.113 \\
\hline \multicolumn{3}{|l|}{ Education } \\
\hline Primary school and lower & 1 & \\
\hline Middle school & $1.039(0.982 \sim 1.100)$ & 0.186 \\
\hline College and higher & $1.048(0.955 \sim 1.149)$ & 0.322 \\
\hline \multicolumn{3}{|l|}{ Occupation } \\
\hline Manual & 1 & \\
\hline Nonmanual & $1.009(0.935 \sim 1.089)$ & 0.814 \\
\hline Unemployed or retired & $1.183(1.092 \sim 1.282)$ & $<0.001$ \\
\hline \multicolumn{3}{|l|}{ Smoker } \\
\hline Never & 1 & \\
\hline Former & $1.116(1.012 \sim 1.230)$ & 0.027 \\
\hline Current & $1.056(0.989 \sim 1.129)$ & 0.102 \\
\hline Drinker (vs. no) & $1.410(1.283 \sim 1.550)$ & $<0.001$ \\
\hline \multicolumn{3}{|l|}{ Physical activity } \\
\hline Insufficient & 1 & \\
\hline Sufficient & $0.945(0.899 \sim 0.993)$ & 0.025 \\
\hline \multicolumn{3}{|l|}{ Sleep duration } \\
\hline$<6$ & 1 & \\
\hline $6-8 \mathrm{~h}$ & $0.940(0.820 \sim 1.079)$ & 0.381 \\
\hline $8-10 \mathrm{~h}$ & $0.976(0.851 \sim 1.120)$ & 0.729 \\
\hline$\geq 10 \mathrm{~h}$ & $1.274(1.075 \sim 1.510)$ & 0.005 \\
\hline
\end{tabular}

Data are represented as OR $(95 \% \mathrm{CI})$. Overweight/obesity: BMI $\geq 24 \mathrm{~kg} / \mathrm{m}^{2}$. OR was calculated with multivariable logistic regression analysis. OR: odds ratio; CI: confidence intervals.

weight and had a greater pressure to keep a slim figure [23]. These data implied that the overweight and obesity management in Baoji area should post 35 to 44-year-old men and postmenopausal women as the priority management groups. Multivariate analysis showed that people who were married or living with a partner were more likely to be overweight/obesity than unmarried people. Previous researches suggested that marriage was associated with weight gain and that divorce and widowhood were associated with weight loss $[24,25]$. While a review indicated that marital transi- tions are more important than marital status in predicting change in body weight, it was found that transition into marriage appears to be associated with weight gain, whereas transition out of marriage is associated with weight loss [26]. Further research is needed to illustrate the relationships between marital transitions and body weight in our study area.

The relationship between smoking and obesity is complex, and published studies have produced conflicting results. Some reported current smokers were less likely to be obese than never smokers [27]; some have shown no significant association between smoking and body mass index [28]; our study is consistent with studies that have found that former smokers were more likely to be obese [29]. These contradictory findings show that the association still requires more attention. Nowadays, recreational alcohol intake is common across the globe, and numerous studies have examined the effect of alcohol intake on obesity. Some previous studies showed no association or a negative association between alcohol intake and weight gain or obesity [30]. In contrast, we found a positive impact of drinking alcohol on overweight/obesity in line with some literatures [31, 32]. Furthermore, other studies have declared that only excessive or heavy drinking is correlated with increased body weight [33]. Apparently, available evidence on the topic is mixed and conflicting, which warrant further exploration.

Our study found a positive association of long sleep duration $(>10 \mathrm{~h})$ on overweight/obesity, in accordance with previous studies [34]. Yet, numerous studies showed a significant increased risk of weight gain with inadequate sleep [35]. Further studies are required to confirm such an association. Physical activity contributes to energy expenditure, prevents obesity, and reduces the risk of major NCDs and decreased all-cause mortality [36]. We found there was a lower incidence of overweight/obesity in participants with a sufficient leisure time physical activity, which is consistent with previous studies [37], while it differs from a study which reported that physical inactivity was inversely associated with overweight but not associated with obesity [17]. Moreover, some found there was no significant correlation between regular physical activity and a lower risk of overweight/obesity [19]. Such findings are probably explained by the difference in criteria used to classify participants as physically active or inactive. Our assessment of physical activity focused on leisure time domain and did not include physical activity in transportation, occupational, and household domains, which are major contributors to total physical activity. Thus, further studies are needed to elucidate the potential effect of inclusion of other types of physical activity. The Chinese government has realized the importance of obesity control and, therefore, has implemented several measures to promote participation in physical activity; figures showed these initiatives have already had some effect [5]. Nevertheless, continued nationwide or local interventions are still needed for promotion of physical activity and other healthy lifestyles.

Several limitations should be noted. First, our study was a cross-sectional design, and therefore, causal relations cannot be established. Second, dietary habits could impact on 
body weight or obesity, and difference in eating habits may be the main reasons for variations in overweight and obesity prevalence across regions. However, we only investigated a few defined major risk factors. In order to better control overweight and obesity, further research is warranted that includes broader factors. Third, as the study is confined to western China, the conclusions from our study cannot represent the situation in other areas in China. Despite these limitations, this is the first study to determine the prevalence of overweight and obesity and explore related factors based on a relatively large sample size in Baoji, which provides important clues for the prevention and control of local obesity.

\section{Conclusions}

In summary, the prevalence of overweight is almost equivalent to that of China and the prevalence of obesity is relatively lower in Baoji district. Factors significantly associated with an increased risk of overweight/obesity were older age, married condition, unemployed or retired, former smoker, drinking alcohol, and sleeping too much, while living in rural areas or having a sufficient physical activity may be a protect factor. This study provides data on current overweight and obesity prevalence and related factors in Baoji city of western China, which may guide the development of practical and effective strategies for managing and preventing overweight and obesity.

\section{Data Availability}

The original data used to support the findings of this study are available from the corresponding author upon request.

\section{Conflicts of Interest}

The authors declare no conflicts of interest related to this work.

\section{Acknowledgments}

This study was supported by the Health Commission of Shaanxi Province (No. 2016D099). We acknowledge the support and help of Health Bureau and CDC of Baoji city and 12 counties as well as the participants for their contribution to the research.

\section{References}

[1] World Health Organization, "Obesity and Overweight fact sheet from the WHO," 2020, https://www.who.int/en/newsroom/fact-sheets/detail/obesity-and-overweight.accessed.

[2] D. T. Chu, N. T. Minh Nguyet, T. C. Dinh et al., "An update on physical health and economic consequences of overweight and obesity," Diabetes \& metabolic syndrome, vol. 12, no. 6, pp. 1095-1100, 2018.

[3] T. Bhurosy and R. Jeewon, "Overweight and obesity epidemic in developing countries: a problem with diet, physical activity, or socioeconomic status?," The Scientific World Journal, vol. 2014, Article ID 964236, 7 pages, 2014.
[4] B. M. Popkin, L. S. Adair, and S. W. Ng, "Global nutrition transition and the pandemic of obesity in developing countries," Nutrition reviews, vol. 70, no. 1, pp. 3-21, 2012.

[5] Y. Tian, C. Jiang, M. Wang et al., "BMI, leisure-time physical activity, and physical fitness in adults in China: results from a series of national surveys, 2000-14," The lancet Diabetes \& endocrinology, vol. 4, no. 6, pp. 487-497, 2016.

[6] C. Chen and F. C. Lu, "The guidelines for prevention and control of overweight and obesity in Chinese adults," Biomedical and environmental sciences: BES, vol. 17, pp. 1-36, 2004.

[7] World Health Organization, Guidelines for Controlling and Monitoring the Tobacco Epidemic, World Health Organization, 1998.

[8] World Health Organization, International Guide for Monitoring Alcohol Consumption and Related Harm, World Health Organization, 2000.

[9] C. E. Kim, S. Shin, H. W. Lee et al., "Association between sleep duration and metabolic syndrome: a cross-sectional study," BMC Public Health, vol. 18, no. 1, p. 720, 2018.

[10] World Health Organization, Global Recommendations on Physical Activity for Health, World Health Organization, 2010.

[11] National Health Commission for Disease Control and Prevention, Chinese residents nutrition and chronic disease status report, People's medical publishing house, Beijing, 1st ed edition, 2015.

[12] R. Wang, P. Zhang, C. Gao et al., "Prevalence of overweight and obesity and some associated factors among adult residents of northeast China: a cross-sectional study," BMJ open, vol. 6, no. 7, article e010828, 2016.

[13] M. J. Jin, B. B. Chen, Y. Y. Mao et al., "Prevalence of overweight and obesity and their associations with socioeconomic status in a rural Han Chinese adult population," PloS one, vol. 8, no. 11, article e79946, 2013.

[14] L. Hu, X. Huang, C. You et al., "Prevalence of overweight, obesity, abdominal obesity and obesity-related risk factors in southern China," PLoS One, vol. 12, no. 9, article e0183934, 2017.

[15] L. Pei, Y. Cheng, Y. Kang, S. Yuan, and H. Yan, "Association of obesity with socioeconomic status among adults of ages 18 to 80 years in rural Northwest China," BMC public health, vol. 15, no. 1, 2015.

[16] L. Zhang, Z. Wang, X. Wang et al., "Prevalence of overweight and obesity in China: results from a cross-sectional study of 441 thousand adults, 2012-2015," Obesity research \& clinical practice, vol. 14, no. 2, pp. 119-126, 2020.

[17] S. Pengpid and K. Peltzer, "Associations between behavioural risk factors and overweight and obesity among adults in population-based samples from 31 countries," Obesity research \& clinical practice, vol. 11, no. 2, pp. 158-166, 2017.

[18] F. Garawi, K. Devries, N. Thorogood, and R. Uauy, "Global differences between women and men in the prevalence of obesity: is there an association with gender inequality?," European journal of clinical nutrition, vol. 68, no. 10, pp. 1101-1106, 2014.

[19] Y. Gao, X. W. Ran, X. H. Xie et al., "Prevalence of overweight and obesity among Chinese Yi nationality: a cross-sectional study," BMC public health, vol. 11, no. 1, p. 919, 2011.

[20] L. Cai, X. Han, Z. Qi et al., "Prevalence of overweight and obesity and weight loss practice among Beijing Adults, 2011," PloS one, vol. 9, article e98744, no. 9, 2014.

[21] M. Maimaiti, X. Zhao, M. Jia, Y. Ru, and S. Zhu, "How we eat determines what we become: opportunities and challenges 
brought by food delivery industry in a changing world in China," European journal of clinical nutrition, vol. 72, no. 9, pp. 1282-1286, 2018.

[22] G. N. Healy, K. Wijndaele, D. W. Dunstan et al., "Objectively measured sedentary time, physical activity, and metabolic risk: the Australian Diabetes, Obesity and Lifestyle Study (AusDiab)," Diabetes care, vol. 31, no. 2, pp. 369-371, 2008.

[23] Y. Wu, R. Huxley, M. Li, and J. Ma, "The growing burden of overweight and obesity in contemporary China," CVD Prevention and Control, vol. 4, no. 1, pp. 19-26, 2009.

[24] J. Sobal, K. L. Hanson, and E. A. Frongillo, "Gender, ethnicity, marital status, and body weight in the United States," Obesity (Silver Spring, Md), vol. 17, no. 12, pp. 2223-2231, 2009.

[25] H. Samouda, M. Ruiz-Castell, V. Bocquet et al., "Geographical variation of overweight, obesity and related risk factors: findings from the European Health Examination Survey in Luxembourg, 2013-2015," PloS one, vol. 13, no. 6, article e0197021, 2018.

[26] L. Dinour, M. M. Leung, G. Tripicchio, S. Khan, and M. C. Yeh, "The association between marital transitions, body mass index, and weight: a review of the literature," Journal of obesity, vol. 2012, Article ID 294974, 16 pages, 2012.

[27] B. Sakboonyarat, C. Pornpongsawad, T. Sangkool et al., "Trends, prevalence and associated factors of obesity among adults in a rural community in Thailand: serial crosssectional surveys, 2012 and 2018," BMC public health, vol. 20, no. 1, p. 850, 2020.

[28] Y. Kim, S. M. Jeong, B. Yoo, B. Oh, and H. C. Kang, "Associations of smoking with overall obesity, and central obesity: a cross-sectional study from the Korea National Health and Nutrition Examination Survey (2010-2013)," Epidemiol Health, vol. 38, article e2016020, 2016.

[29] S. Dare, D. F. Mackay, and J. P. Pell, "Relationship between smoking and obesity: a cross-sectional study of 499, 504 middle-aged adults in the UK general population," PLoS One, vol. 10, no. 4, article e0123579, 2015.

[30] S. Yu, L. Xing, Z. du et al., "Prevalence of obesity and associated risk factors and cardiometabolic comorbidities in rural Northeast China," BioMed Research International, vol. 2019, Article ID 6509083, 9 pages, 2019.

[31] K. C. Sung, S. H. Kim, and G. M. Reaven, "Relationship among alcohol, body weight, and cardiovascular risk factors in 27, 030 Korean men," Diabetes care, vol. 30, no. 10, pp. 2690-2694, 2007.

[32] Y. Wang, L. Pan, S. Wan et al., "Increasing prevalence of overweight and obesity in Yi farmers and migrants from 2007 to 2015 in China: the Yi migrant study," BMC public health, vol. 18, no. 1, p. 659, 2018.

[33] S. G. Wannamethee, A. G. Shaper, and P. H. Whincup, "Alcohol and adiposity: effects of quantity and type of drink and time relation with meals," International journal of obesity, vol. 29, no. 12, pp. 1436-1444, 2005.

[34] D. Léger, F. Beck, J. B. Richard, F. Sauvet, and B. Faraut, “The risks of sleeping "too much". Survey of a National Representative Sample of 24671 adults (INPES health barometer)," PloS one, vol. 9, no. 9, article e106950, 2014.

[35] K. L. Knutson, "Does inadequate sleep play a role in vulnerability to obesity?," American journal of human biology: the official journal of the Human Biology Council, vol. 24, no. 3, pp. 361-371, 2012.
[36] M. Q. Waleh, "Impacts of physical activity on the obese," Primary care, vol. 43, no. 1, pp. 97-107, 2016.

[37] F. Liu, W. Wang, J. Ma, R. Sa, and G. Zhuang, "Different associations of sufficient and vigorous physical activity with BMI in Northwest China," Scientific reports, vol. 8, no. 1, article 13120, 2018. 